\title{
EVALUATION OF INTERNAL COHESION OF MULTIPHASE PLASMA-SPRAYED COATINGS BY CAVITATION TEST: FEASIBILITY STUDY
}

\author{
RAdeK MušÁleK $^{a, *}$, Emanuele NardozzA ${ }^{b}$, Tomáš TesaŘ $^{a, c}$, \\ JAN MEDŘICKÝ ${ }^{a, c}$ \\ ${ }^{a}$ Czech Academy of Sciences, Institute of Plasma Physics, Department of Materials Engineering, Za Slovankou \\ 1782/3, 18200 Prague 8, Czech Republic \\ ${ }^{b}$ University of Modena and Reggio Emilia, Faculty of Materials Engineering, via Pietro Vivarelli 10, Modena, \\ Italy \\ ${ }^{c}$ Czech Technical University in Prague, Faculty of Nuclear Sciences and Physical Engineering, Trojanova 13, \\ 12000 Prague, Czech Republic \\ * corresponding author: musalek@ipp.cas.cz
}

\begin{abstract}
Mechanical characterization of plasma-sprayed coatings at microscopic level represents a major challenge due to the presence of numerous inherent microstructural features such as cracks, pores, or splat boundaries, which complicate coatings characterization by conventional testing methods. Need for reliable testing of structural integrity of newly developed multiphase plasma-sprayed coatings introduced even more complexity to the testing. In this study, applicability of indirect vibratory cavitation test (adapted from ASTM G32 standard) for such testing was evaluated. Three plasmasprayed coatings having distinctive microstructures were tested: i) conventional alumina coating deposited from coarse powder, ii) hybrid coating deposited by co-spraying of coarse alumina powder and fine yttria-stabilized zirconia (YSZ) suspension, and iii) compact alumina coating deposited from fine ethanol-based suspension. Differences in the coatings internal cohesion were reflected in different failure mechanisms observed within the cavitation crater by scanning electron microscopy and mean erosion rates being i) $280 \mu \mathrm{m} /$ hour, ii) $97 \mu \mathrm{m} /$ hour and iii) $14 \mu \mathrm{m} /$ hour, respectively.
\end{abstract}

KEYWORDS: Cavitation damage, cohesion, failure analysis, plasma spray coatings.

\section{INTRODUCTION}

Plasma-sprayed coatings belong to the family of thermal sprayed materials and are used in numerous applications, typically to protect the substrate material from the aggressive environments. Thermal barrier coatings or wear-resistant coatings may be listed as typical examples. They often contain numerous voids (pores and cracks) which are desirable from the functional point of view (e.g. providing strain tolerance or decreasing thermal conductivity) but together with rather low coating thickness make evaluation of coatings mechanical properties quite challenging. Hardness testing may serve as a good illustration [1]. For high loads, indent size may be higher than the available coating thickness or lead to excessive coating cracking. On the other hand, for small loads, hardness values may be not representative of the whole coating microstructure as the loaded volume contains only individual splats. This applies for both conventional and instrumented indentation. Another example can be adhesion/cohesion testing of the coatings by so called "pull-test" [2], where the coating is glued to the dummy counter-part and loaded across the interface until failure. This test is widely used for thermally sprayed coatings, but may provide highly unreliable results for coatings which are porous, thin, or have adhesion/cohesion higher than strength of the available glue (typically 70-80 MPa) [3]. Unfortunately, it is quite common that novel coatings meet at least one of the above mentioned criteria.

It is therefore desirable to seek for new types of tests which may be applied for plasma-sprayed coatings and provide measure of the coatings durability (integrity) reflecting internal coating cohesion and/or adhesion to the substrate. Such test should be highly repeatable, representative for the whole coating, economical, and easy to perform on samples with simple geometry with coatings having as-sprayed as well as finished surface. It should also mimic loading mode in some typical coating application. Recently, vibratory cavitation test emerged as a potential candidate [4 6]. It may be relatively easily adapted and simulates conditions in applications where the cavitation occurs, such as hydraulic turbines, pumps, steering rudders, etc. 7, 8. Sample (in this case a coated part) is immersed into appropriate liquid and its surface is repeatedly exposed to aggressive pressure waves generated by collapse of cavitation bubbles. In the "direct cavitation setup", cavitation is induced by high-frequency oscillations of the sample itself. For testing of coated samples, "indirect cavitation setup" (also denoted as "alternative setup") is more suitable. In this setup, 


\begin{tabular}{llllll}
\hline Coating & \multicolumn{1}{c}{ Feedstock type } & $\begin{array}{l}\mathrm{FD} \\
(\mathrm{mm})\end{array}$ & $\begin{array}{l}\mathrm{SD} \\
(\mathrm{mm})\end{array}$ & $\begin{array}{l}\mathrm{FR} \\
(\mathrm{kg} / \mathrm{h})\end{array}$ & $\begin{array}{l}\mathrm{CT} \\
(\mu \mathrm{m})\end{array}$ \\
\hline $\mathrm{AW} 24$ & $\mathrm{Al}_{2} \mathrm{O}_{3}$ powder / - & $55 /-$ & 380 & $8.8 /-$ & $327 \pm 16$ \\
$\mathrm{SR} 086$ & $\mathrm{Al}_{2} \mathrm{O}_{3}$ powder / YSZ suspension & $35 / 20$ & 130 & $7.0 / 6.7$ & $771 \pm 10$ \\
$\mathrm{SR} 119$ & $-/ \mathrm{Al}_{2} \mathrm{O}_{3}$ suspension & $-/ 25$ & 100 & $-/ 6.0$ & $167 \pm 10$ \\
& & & & \\
Note: FD - Feeding distance, SD - Spraying distance, & FR - Feed Rate, CT - Coating thickness. \\
\hline
\end{tabular}

TABLE 1. Spraying conditions for powder/suspension.

exchangeable tip made of durable material is placed over the sample and its vibrations form stream of cavitation bubbles which erode the sample surface (Figure 17). As described by ASTM G32 standard [9], durability of tested materials may be then evaluated in terms of their mass loss against exposure time or some other characteristics derived from this curve. For testing of plasma-sprayed coatings, it is also interesting that individual cavitation bubbles erode the tested coating at microscopic scale (reflecting the coatings microstructure), but at the same time, their number is high enough to provide representative coatings characteristics.
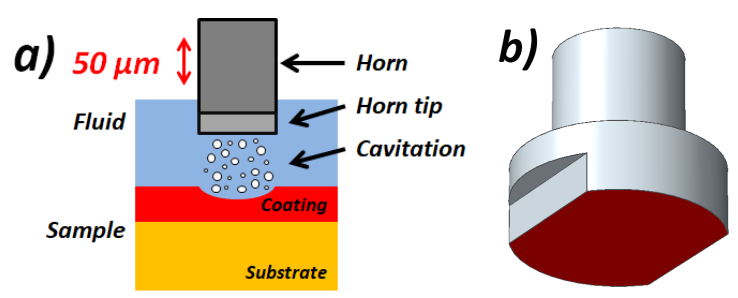

FIGURE 1. a) Schematic of the indirect cavitation test for a coated sample. b) Geometry of used horn tip - red area $\left(115.7 \mathrm{~mm}^{2}\right)$ is closest to the sample and emitting cavitation bubbles.

Aim of this study was to test applicability and sensitivity of the vibratory cavitation test for evaluation of novel multiphase plasma-sprayed coatings. Test was applied on three ceramic coatings which were expected to have greatly different resistance against cavitation.

\section{EXPERIMENTALS}

Three coatings were prepared on grit-blasted steel coupons $\left(20 \times 30 \times 2.5 \mathrm{~mm}^{3}\right)$ by hybrid waterstabilized plasma (WSP-H) torch WSP-H 500 (ProjectSoft HK, a.s., Czechia). Coating AW24 was a conventional $\mathrm{Al}_{2} \mathrm{O}_{3}$ coating sprayed from coarse dry powder, coating SR086 was experimental multiphase coating prepared by "hybrid" co-spraying of coarse dry $\mathrm{Al}_{2} \mathrm{O}_{3}$ and fine YSZ (yttria-stabilized zirconia) suspension, and coating SR119 was dense $\mathrm{Al}_{2} \mathrm{O}_{3}$ coating deposited from fine suspension. Materials used for spraying were SURPREX AW24 powder (Fujimi INC., Japan, granulometry $-75+38 \mu \mathrm{m}), 25 \%$ YSZ suspension in ethanol (Treibacher Industrie AG, Austria, mean particle size $\sim 0.5 \mu \mathrm{m})$ and ethanol-based $10 \%$ suspension of $\mathrm{Al}_{2} \mathrm{O}_{3}$ (Allied High Tech Products
INC., USA, mean particle size $\sim 0.3 \mu \mathrm{m})$. Principal deposition parameters are listed in Table 1 . For details, see [10 12].

Scanning electron microscope (SEM) EVO MA 15 (Carl Zeiss SMT, Germany) was used for structural observations using back-scattered electron detection mode.

Cross-sections and free-surfaces of the coatings (Figure 2 show substantial differences in the coatings microstructures. Coating AW24 sprayed from coarse powder showed conventional lamellar microstructure with large alumina splats and numerous intersplat and intrasplat cracks and pores. Hybrid coating SR086 consisted of large alumina splats originating from coarse powder interconnected on their surface by miniature YSZ splats originating from fine suspension. Coating SR119 sprayed from fine suspension showed densely packed splats. Their reduced size effectively suppressed formation of intrasplat cracks, which are typical for splats sprayed from coarse powders due to development of quenching stresses [13, 14] - compare AW24 and SR119 in Fig. 2.

Cavitation test was carried out according to the modified ASTM G32-16 test in "indirect cavitation" setup [9]. The horn tip made of durable titanium alloy was placed over the sample and its vibration formed stream of cavitation bubbles which eroded the sample. All samples were tested in as-sprayed condition, i.e. without any surface polishing. Samples were weighted, immersed in distilled water $\left(25 \pm 2{ }^{\circ} \mathrm{C}\right)$ and put under the horn tip so that the spacing between the horn tip and the sample surface was $0.6 \mathrm{~mm}$. Formation of cavitation bubbles was imposed by vibration of the horn tip with frequency of $\mathrm{f}=20 \mathrm{kHz}$ and peak-to-peak amplitude Apeak-peak $=50 \mu \mathrm{m}$. After preselected time interval, samples were taken out, rinsed and dried with hot air, and weighted again. The whole procedure was repeated several times until considerable revelation of the substrate. ASTM G32-16 standard prescribes shape of the horn tip as circular $(\varnothing 15.9 \mathrm{~mm}$, area $198.6 \mathrm{~mm}^{2}$ ). In this test, tip geometry was modified (cropped circle $\varnothing 13 \mathrm{~mm}$, area $115.7 \mathrm{~mm}^{2}$ - see Figure 1 b) to fit the whole eroded area within the coated surface. In order to compensate for difference in tip geometry, erosion rates (in g/hour) were normalized by coating density and horn tip area providing mean erosion rate (in $\mu \mathrm{m} /$ hour). 

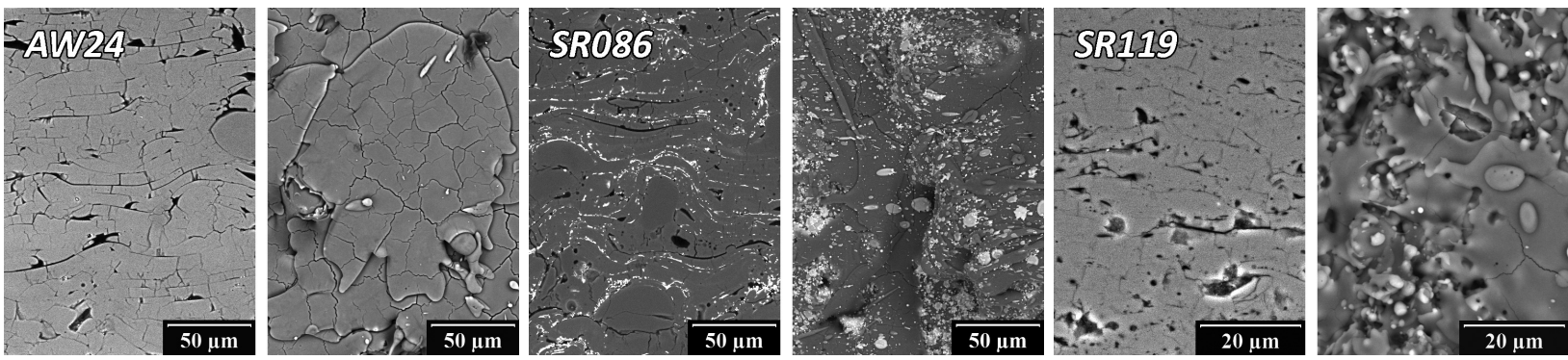

FiguRE 2. Coatings microstructure. Cross-section (left) and free-surface (right). Bright spots in SR086 coating are YSZ splats. SEM.
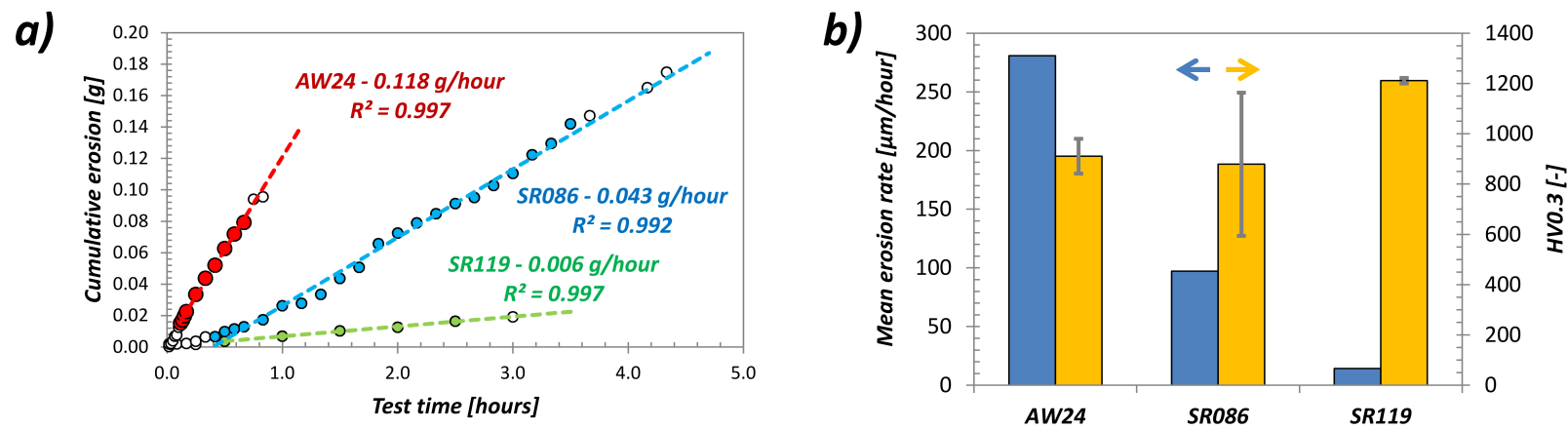

Figure 3. a) Cumulative erosion vs time curves. Filled points were used for linear fit. b) Erosion rates (blue) and coating microhardness values (yellow).

\section{Results AND Discussion}

Obtained experimental curves of cumulative mass loss versus cumulative exposure time are compared for all three coatings in Figure 3a. None of the coatings showed considerable incubation period and, in all cases, the coating weight loss closely followed linear trend in time. For the hybrid coating SR086, high number of measurements enabled detection of minor acceleration stage at the beginning of the test, but the erosion rate stabilized soon. At the terminal stage of the test, substrate started to be revealed for all coatings (Figure 4), so data points only from the central part of the experimental curves were fitted by linear dependency. This enabled to quantify the coatings durability in terms of erosion rate in g/hour (Figure 3 a) which could be with knowledge of theoretical coating density and area of horn tip transformed into mean thickness loss in $\mu \mathrm{m}$ per hour (Figure $3 \mathrm{p}$ ).

From the obtained erosion rates and appearance of cavitation craters (Figure 4 to 6), following conclusions may be stated:

- As expected, coating AW24 with rather loose microstructure showed the lowest cavitation resistance with erosion rates reaching $118 \mathrm{mg} /$ hour or $280 \mu \mathrm{m} /$ hour. Relatively low adhesion of the coating to the substrate was at the end of the test reflected also on large-scale revelation of the substrate under the cavitation crater. Coating showed tendency to fail by initial formation of wide cavitation pits which was soon followed by coating detachment in large crumbled pieces.
- For coating SR086, different deposition conditions (in particular lower spraying distance) and addition of secondary phase promoted mutual bonding of the splats which led to decrease of cavitation rate to $43 \mathrm{mg} /$ hour or $97 \mathrm{\mu m} /$ hour. Also, failure mode of the coating was different as it showed tendency to fail by exfoliation which formed noticeable steps on the sides of the cavitation crater. These possibly followed the interfaces generated during the coating deposition between sub-layers formed by consecutive spraying passes.

- For coating SR119, cavitation rate further dropped to just about $6 \mathrm{mg} /$ hour or $14 \mu \mathrm{m} /$ hour. These low values confirmed high structural integrity of the coating. It may be noted that the same coating showed in "pull-test" (ASTM C633) extreme tensile adhesion/cohesion strength of about $51 \mathrm{MPa}$ [10]. High cohesion of the coating was reflected also in its different failure mode, as the cavitation crater was formed by numerous narrow pits which only slowly propagated into the coating.

In Figure 3p, mean erosion rates may be related also to the coatings microhardness values. As expected, the most compact coating SR119 showed the highest hardness whereas the multiphase nature of hybrid coating was reflected in high scatter of microhardness values. It may be therefore concluded that cavitation test seems to convincingly reflect differences in the internal microstructure of the plasma-sprayed coatings and in particular their internal cohesion.

Qualitatively different response of the coatings to 

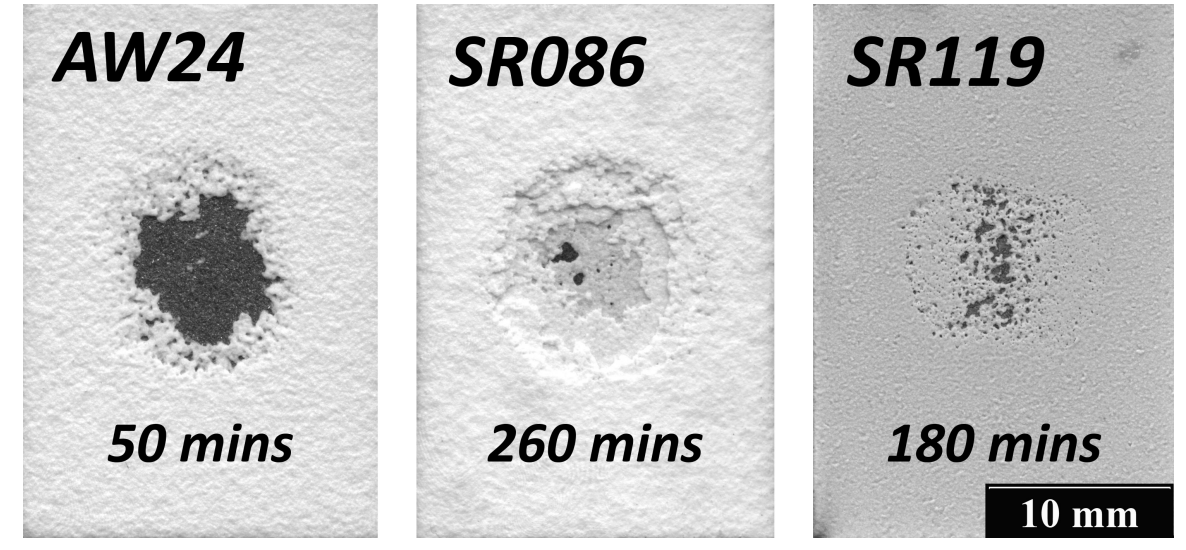

Figure 4. Eroded samples (overview) at the end of the test. Total exposure time in minutes.
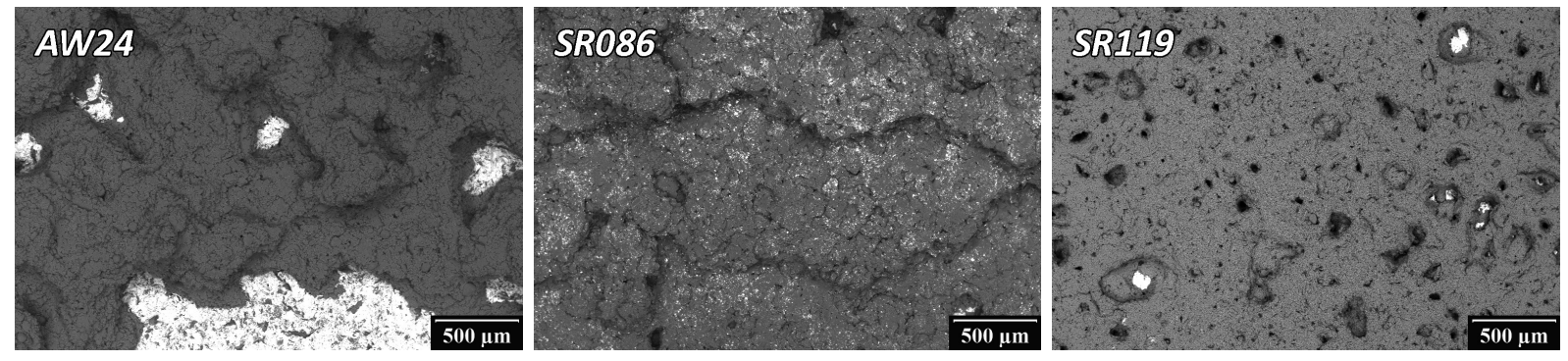

FIGURE 5. Rim of cavitation crater after the test. Bright spots are the revealed substrate. SEM.
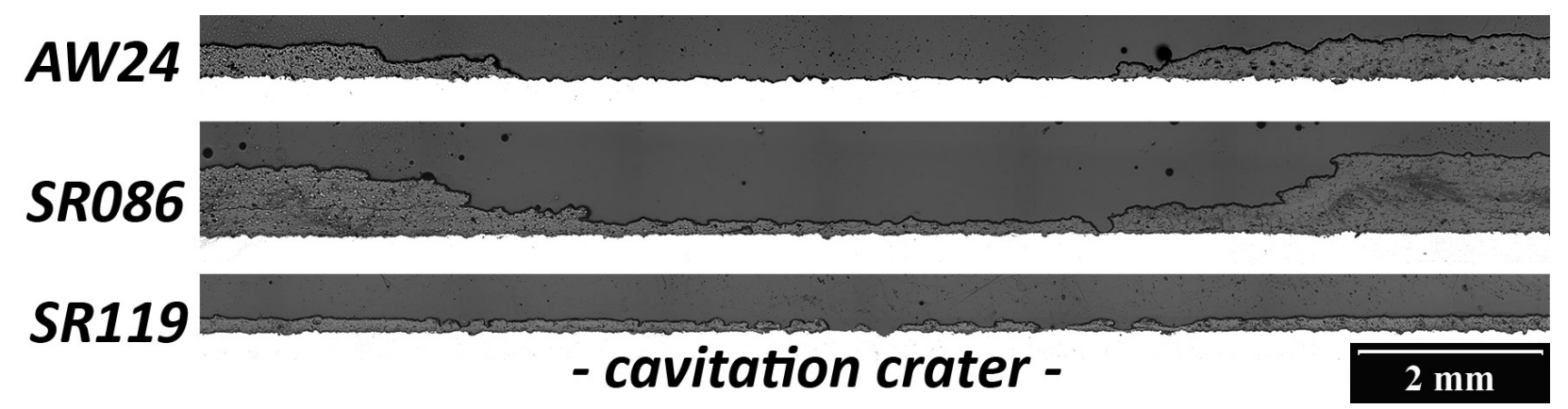

FiguRE 6. Cross-sections through cavitation crater after the test. Light microscopy.

the cavitation loading may be observed also from micrographs of the damaged free-surfaces and their cross-sections (Figure 7). In case of AW24 coating, numerous internal voids (intrasplat cracks in particular) and weak bonding between splats promoted crushing of the splats and their mutual debonding. In case of SR086 coating, the failure was possibly delayed by improved bonding of splats due to presence of secondary YSZ phase. Good bonding between alumina and YSZ may be assumed from the persevering presence of numerous miniature YSZ splats on the surfaces of heavily eroded alumina splats. However, when the cavitation damage reached weakened interpass (sub-layer) interfaces or areas with locally deficient YSZ phase, in-plane failure was promoted leading to detachment of the coating in large platelets and eventually formation of noticeable steps on the sides of the cavitation crater. On the eroded surface of SR119 coating, heavily crushed miniature splats could be observed which corresponds to high exposure time, but no large-scale damage of the coating microstructure was observed deeper in the coating.

As apparent from Figures 4 to 6, when the cavitation damage reached the substrate, cavitation crater had tendency to widen rather than to penetrate deeper into the substrate. Substrate below the coatings was thus effectively exposed clearly revealing morphology of its originally grit-blasted surface which could be easily identified from the presence of embedded sharpedged grit-blasting particles (Figure 8a). In several isolated locations, formation of shallow pits penetrating the substrate was also detected (Figure 8b). Signs of plastic deformation and attack of grain boundaries could be observed at the bottom of these pits. Nevertheless, negligible loss of the substrate material explains why the apparent linearity of the mass loss curves was not compromised even at the terminal stage of the cavitation test when the substrate started to be exposed. 

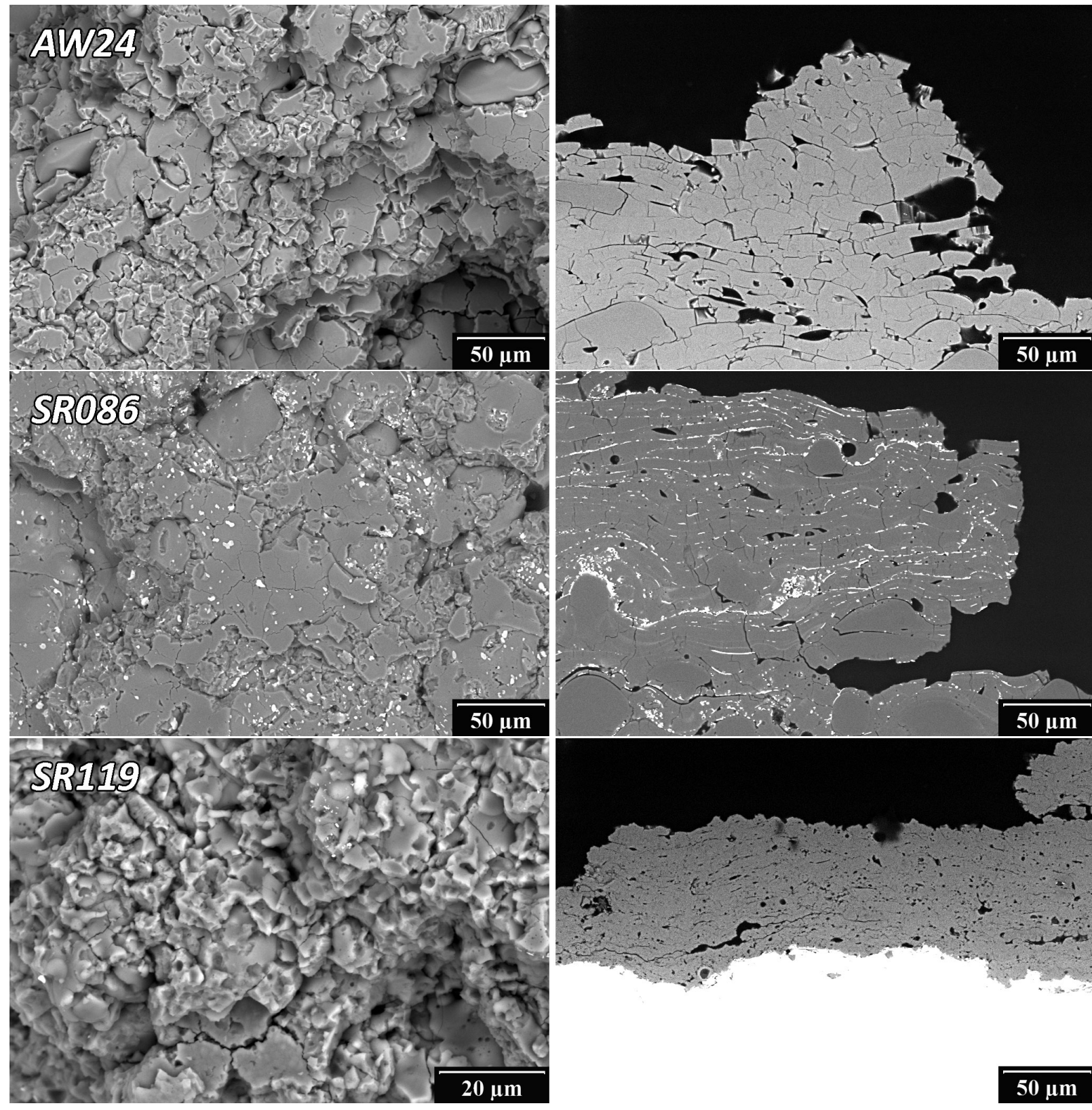

Figure 7. Coating damaged by cavitation. Free-surface (left) and cross-section (right). SEM.
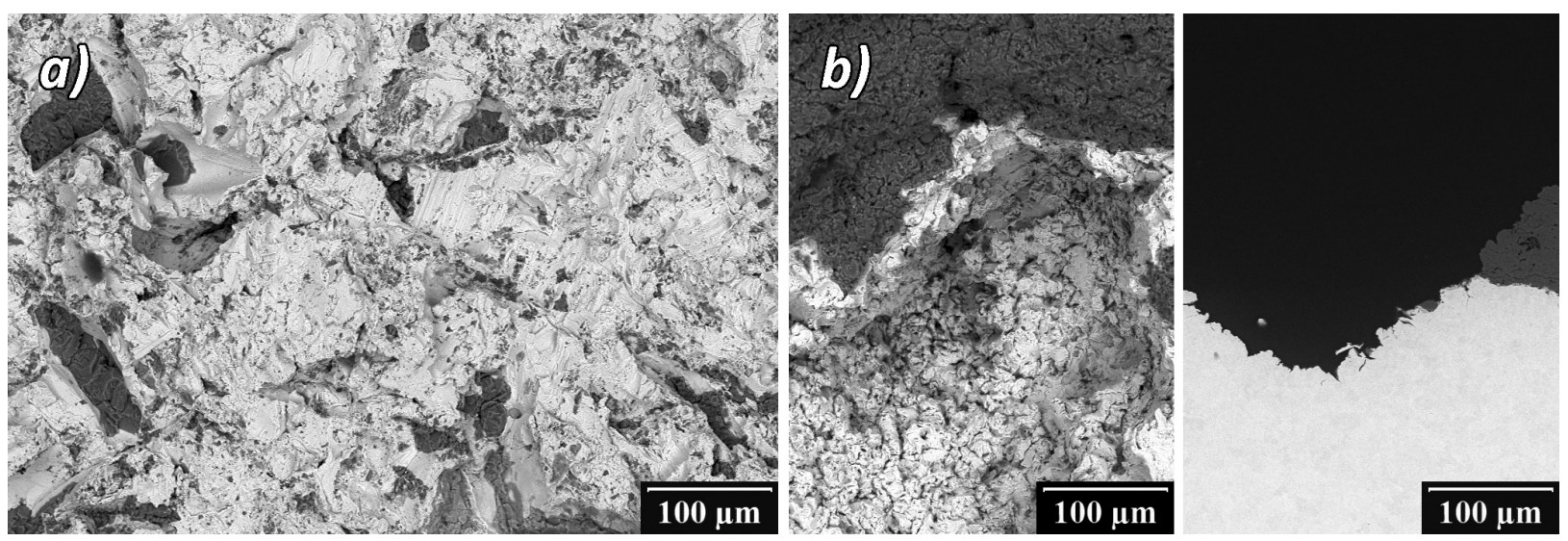

FIGURE 8. a) Exposure of the original grit-blasted substrate surface at the bottom of the cavitation crater (coating AW24). b) Cavitation pit penetrating substrate (coating SR119). Free-surface (left) and cross-section (right). SEM. 


\section{Conclusions}

Indirect vibratory cavitation test adapted from ASTM G32 standard was proven to be potentially valuable for screening of novel plasma-sprayed coatings deposited by hybrid water-stabilized plasma torch. Test could be easily carried out on as-sprayed samples with various thicknesses and without finishing (i.e. polishing) of the surfaces. Cavitation test reflected well the differences in the coatings microstructures. Testing confirmed excellent durability of dense alumina coating deposited from ethanol-based suspension and also indicated that introduction of secondary miniature YSZ phase in so-called hybrid coatings may, together with short spraying distance, improve internal cohesion of the plasma-sprayed alumina.

\section{ACKNOWLEDGEMENTS}

Financial support provided through Czech Science Foundation project 19-10246S "Deposition mechanisms and properties of multiphase plasma sprayed coatings prepared with liquid feedstocks" is gratefully acknowledged.

\section{REFERENCES}

[1] J. Nohava, R. Musalek, J. Matejicek, M. Vilemova. A contribution to understanding the results of instrumented indentation on thermal spray coatings case study on $\mathrm{Al}_{2} \mathrm{O}_{3}$ and stainless steel. Surface and Coatings Technology 240:243 - 249, 2014. DOI:10.1016/j.surfcoat.2013.12.033.

[2] Standard test method for adhesion or cohesion strength of thermal spray coatings, american society for testing and materials (astm), c633 - 13, 2017. DOI:10.1520/C0633-13R17.

[3] R. Musalek, V. Pejchal, M. Vilemova, J. Matejicek. Multiple-approach evaluation of wsp coatings adhesion/cohesion strength. Journal of Thermal Spray Technology 22:221-232, 2013. DOI:10.1007/s11666-012-9850-2

[4] V. Matikainen, S. R. Peregrina, N. Ojala, et al. Erosion wear performance of WC-10Co4Cr and Cr3C2$25 \mathrm{NiCr}$ coatings sprayed with high-velocity thermal spray processes. Surface and Coatings Technology 370:196 - 212, 2019. DOI:10.1016/j.surfcoat.2019.04.067

[5] V. Matikainen, K. Niemi, H. Koivuluoto, P. Vuoristo. Abrasion, erosion and cavitation erosion wear properties of thermally sprayed alumina based coatings. Coatings 4:18-36, 2014. DOI:10.3390/coatings4010018.

[6] J. Kiilakoski, J. Puranen, E. Heinonen, et al. Characterization of powder-precursor HVOF-Sprayed $\mathrm{Al}_{2} \mathrm{O}_{3}-\mathrm{YSZ} / \mathrm{ZrO}_{2}$ coatings. Journal of Thermal Spray Technology 28:98-107, 2019. DOI:10.1007/s11666-018-0816-x

[7] G. L. Chahine, J.-P. Franc, A. Karimi. Laboratory Testing Methods of Cavitation Erosion, pp. 21-35. Springer Netherlands, Dordrecht, 2014. DOI:10.1007/978-94-017-8539-6_2.

[8] H.-B. Lee, C.-S. Park, S.-M. Son, et al. Combatting rudder erosion with cavitation-resistant coating. Journal of Protective Coatings \& Linings 32(3):38-41, 2015.

[9] ASTM G32 - 16 standard test method for cavitation erosion using vibratory apparatus, 2016. DOI:10.1520/G0032-16.

[10] T. Tesar, R. Musalek, J. Medricky, et al. Development of suspension plasma sprayed alumina coatings with high enthalpy plasma torch. Surface and Coatings Technology 325:277 - 288, 2017. DOI:10.1016/j.surfcoat.2017.06.039

[11] R. Musalek, J. Medricky, T. Tesar, et al. Suspensions plasma spraying of ceramics with hybrid water-stabilized plasma technology. Journal of Thermal Spray Technology 26:37-46, 2017. DOI:10.1007/s11666-016-0493-6

[12] J. Medricky, R. Musalek, M. Janata, et al. Cost-effective plasma spraying for large-scale applications. in: ITSC 2018 - Proc. Int. Therm. Spray Conf., Orlando, Florida, pp. 683-689. 2018.

[13] S. Kuroda, T. Clyne. The quenching stress in thermally sprayed coatings. Thin Solid Films 200(1):49 - 66, 1991. DOI:10.1016/0040-6090(91)90029-W

[14] R. Musalek, J. Medricky, T. Tesar, et al. Controlling microstructure of yttria-stabilized zirconia prepared from suspensions and solutions by plasma spraying with high feed rates. Journal of Thermal Spray Technology 26(8):1787-1803, 2017. DOI:10.1007/s11666-017-0622-x. 